\title{
MÁS ALLÁ DE LA TÉCNICA: SÍMBOLO Y LENGUAJE DEL ARTE PALEOLÍTICO
}

\author{
Beyond the technique: Symbols and languages in the Palaeolithic art
}

\author{
Clara Hernando Álvarez \\ Becaria de investigación FPU \\ Dpto. de Prehistoria, $\mathrm{H}^{\mathrm{a}}$ Antigua y Arqueología \\ Universidad de Salamanca \\ E-mail: clara85@usal.es
}

Fecha de recepción: 6-III-2011

Fecha de aceptación: 24-III-2011

Resumen: El título del Congreso, "Razón, utopía y sociedad" responde a tres perspectivas de análisis que han conformado la investigación del Arte paleolítico a lo largo de su poco más de un siglo de vigencia científica. La razón llevó a los primeros prehistoriadores a establecer clasificaciones cronológicas basadas en presunciones estilísticas y técnicas. Frente a ello, surgieron los 'utópicos', aquellos arqueo-etnógrafos que pretendían dar explicaciones actuales a los primeros gestos gráficos de la Humanidad. Del estudio de las denominadas 'culturas primitivas' se han obtenido conocimientos teóricos aplicables, pero también numerosas incongruencias y anacronismos, nada justificados. La presente comunicación pretende una revisión historiográfica crítica de estos 'caminos' de la razón y la utopía con el objeto de acercarnos a la sociedad que hay detrás del arte. Una sociedad comunicada y comunicante, con un lenguaje propio, codificado por la colectividad y estructurado por sus emisores.

Palabras clave: Historiografía crítica, paradigmas, arte paleolítico, sociedad, estructura.

AвstRACt: The title of this congress, "Reason, Utopia and Society" alludes also to the three main analytical perspectives in the study of Palaeolithic art over the century of history of this discipline. Reason first guided prehistorians towards chronological typologies based on stylistic and technical criteria. Utopians arose against this trend, seeking to use archaeoethnographical studies in order to explain these first graphic manifestations of humanity. The study of archaic cultures has provided useful theoretical knowledge, but it is also a 
source of inconsistent anachronisms. This article carries out a critical historiographical review of this ways of Reason and Utopia in order to approach the Society behind Paleolithic art, a communicated and communicative society with its own language, codified by the community and structured by its users.

Key words: Critical historiography, paradigms, palaeolithic art, society, structure.

\section{INTRODUCCIÓN}

Durante un siglo de vida de la disciplina científica del arte paleolítico, pocos son los trabajos destinados a la formación de los conceptos, a la búsqueda de los contextos de construcción histórica, a la crítica historiográfica y más aún, a su epistemología. La investigación actual y nuestra posición ética respecto al ser arqueólogo/prehistoriador ${ }^{1}$, hace necesario dirigir nuestra vista hacia la historia de la disciplina. Pues como expresa P. Bourdieu, "un auténtico revolucionario en materia científica es alguien que tiene un gran dominio de la tradición y no alguien que hace tabla rasa del pasado, o más aún simplemente, lo ignora" ". El título de este congreso, en el que se enmarca la presente comunicación, Razón, utopía y sociedad, nos ha dado la clave para poder encuadrar tres períodos esenciales en la construcción historiográfica del arte paleolítico hasta la actualidad.

\section{LA RAZÓN Y EL "PARADIGMA DE LA SIMPLICIDAD”}

N. Richard definió en 1993 el paradigma de la simplicidad como un doble fenómeno, cultural y biológico de evolución o progreso unilineal; "une chaîne unique de complexité réguliérement croissante" mentalidad, presente en el campo intelectual del siglo XIX, es resultado del transformismo lineal, matriz teórica omnipresente en todas las áreas de la investigación. Emplearemos, pues, dicho concepto para referirnos al transcurrir de los años desde 1864 (fecha de la aceptación del arte mueble como parte de la cultura material paleolítica) a 1902-1903, en que suceden dos hechos 'trascendentales': el reconocimiento del arte parietal paleolítico, mediante la publicación del "La grotte d' Altamira, mea culpa d' un scéptique" de E. Cartailhac ${ }^{4}$ y el nacimiento de las teorías mágicas de S. Reinach.

1 "Hacer arqueología es realizar una práctica interpretativa, una intervención activa involucrada en un proceso crítico de labor teóricas que vincula el pasado y el presente" en LLUL, V. y MICÓ, R. (2001/2002), “Teoría arqueológica III. Las primeras arqueologías posprocesuales" en Revista d'Arqueologia de Ponent, 11-12. (p. 28).

2 BOURDIEU, P. (2000-01), El oficio del cientifico. Ciencia de la ciencia y reflexibilidad. Anagrama. Barcelona. (p. 37).

3 RICHARD, N. (1993), "Del l'art ludique à l'art magique. Interpretations de l'art pariétal au XIX siècle" en Bulletin de la Société Prehistorique Française, 90 (1). (p. 60).

4 CARTAILHAC, E. (1902), "Les cavernes ornées de dessins. La grotte d'Altamira, mea culpa d'un scéptique” en L'Anthropologie, XIII. (p. 348-354). 
En 1864, E. Lartet y H. Christy publican las primeras piezas decoradas de arte paleolítico sobre artefactos muebles: hueso, plaquetas...etc ${ }^{5}$. ¿Cómo dar cabida a esta realidad arqueológica en el marco de las teorías vigentes? El hombre prehistórico, "recién salido de la animalidad" no podía ser artífice de un arte en el sentido en que éste era concebido en el XIX. Apenas había cumplido un siglo el "Modern sistem of art", apoyado en la distinción fundamental entre el 'arte' (Bellas Artes) y el artesanado (artes populares)'. El primero de ellos se asociaba a la inspiración y genialidad de sus autores, miembros de la burguesía y acaparadores del capital científico ${ }^{7}$ de la época. El segundo, era referente del savoir-faire, de la ingenuidad y el utilitarismo de la clase popular ${ }^{8}$. Además, había sido aceptada la 'doctrina ornamental' para los pueblos aborígenes de Oceanía y de África, permitiendo la aceptación de su arte como una artesanía de pequeño formato. La fórmula era clara, la burguesía mantendría su capital simbólico unido al arte, mientras que el hombre paleolítico ('el primitivo') sería asimilado al salvaje moderno ${ }^{10}$. La teoría transformista prevalecerá generando la disyuntiva entre 'lo artístico' y 'lo primitivo', que tendría su correspondencia en el surgimiento de las primeras cronologías (elaboradas por G. Mortillet y E. Piette) e interpretaciones del arte (el arte por el arte).

La inexistencia del arte parietal hasta 1902, a pesar del descubrimiento y publicación de Altamira por M. S. Sautuola ${ }^{11}$, es el resultado del consenso

5 LARTET, E. y CHRISTY, H. (1864), «Sur des figures animaux gravées ou sculpées et autres produits d'Art et d'industrie rapportables aux temps primordiaux de la période humaine » en Revue Archéologique. Libraire Académique Didier et Cie. Paris. (p. 1-37).

6 SHINER, L. (2001), The Invention of Art. A Cultural History. The University of Chicago Press, Chicago. (p. 3).

7 “capital científico" es una expresión que aplica P. Bourdieu para referirse a los conocimientos y aptitudes personales que crean el campo de posibilidades de la Ciencia. BOURDIEU, P. (1994), Razones prácticas sobre la teoría de la acción. Barcelona, Anagrama.

8 MORO ABADÍA, O. y GONZÁLEZ MORALES, M. R. (2005), "Presente-pasado. Definición y usos de una categoría historiográfica en la historia de la ciencia: El arte prehistórico como paradigma" en Complutum, 16. (p. 65).

9 DAGEN, P. (1998). Le Peintre, le Poète, le Sawvage. Les Voies du Primitivisme dans L'art Français. Flammarion, Paris. (p. 39).

10 "En el esquema de pensamiento occidental, la definición del hombre prehistórico y de los 'modernos salvajes' aparece ligada a la noción de 'primitivo'. Los primeros son primitivos alejados en el tiempo, los segundos, primitivos alejados en el espacio" en MORO ABADÍA, O. y GONZÁLEZ MORALES, M. R. (2005), ídem. (p. 67).

11 SANZ DE SAUTUOLA, M. (1880), Breves apuntes sobre algunos objetos prehistóricos de la provincia de Santander. Telesforo Martínez, Ed. 
científico alcanzado por grandes personalidades ${ }^{12}$ como G. Mortillet y E. Cartailhac (maestro y discípulo respectivamente). E. Piette, en 1880, presenta un esquema de explicación del arte paleolítico que evoluciona hacia la perfección técnica. La ordenación se establece situando en el inicio de la cadena la escultura, seguida del bajo-relieve, siendo el último eslabón el dibujo (pues éste necesitaba de un grado mayor de abstracción). Dicha secuencia reside en la idea de que el hombre primitivo no está desarrollado intelectualmente para el proceso de abstracción. El paradigma imperante sólo cambió a la muerte de G. Mortillet en 1898 pues "la reconnaissance d'un art aussi ancien et aussi elaboré ne pouvait s'effectuer sans revision du strict transformisme de Mortillet, qui voyait un parallélisme absolu entre évolution culturelle et évolution des capacités intellectuales de l'homme"13.

Uno de los primeros autores en pronunciarse sobre la posible significación del grafismo paleolítico fue E. Cartailhac ${ }^{14}$, quien interpretó que los grupos humanos cubrían ampliamente sus necesidades mediante la caza y la pesca; disfrutando de tiempo libre, sinónimo de una existencia poco atormentada. En la misma línea interpretativa, E. Lartet y H. Christy juzgaron estas primeras obras de arte como el producto del ocio de unos cazadores que vivían en un ambiente rico en animales, de los que se alimentaban, y a los que sobraría el tiempo ${ }^{15}$. Ambos investigadores, junto con E. Piette, defendían que el hombre paleolítico no se movía por sentimientos religiosos, además de no poder tener pensamientos tan elaborados. No podía hablarse aún de 'religiosidad' porque 'l'anticléricalisme militant de préhistoriens éminents, tel Gabriel de Mortillet, en des temps où la lutte était vive entre les tenants d'une préhistoire antidiluvienne et l'Eglise, leur faisait refuser toute aspiration religieuse chez les préhistoriques" ". Es por ello, que el arte fue concebido como algo puramente decorativo y fruto del carácter ocioso de sus autores. De esta reflexión surgió la hipótesis del "arte por el arte", protagonista del un período que abarcaría desde el descubrimiento del arte mueble paleolítico en 1864, hasta la publicación del artículo de S. Reinach "L'art et la magie"'.

12 La centralización del poder simbólico ha sido explicada por N. Richard como "les poids des personnalités” (en RICHARD, N. (1992), «L'institutionalisation de la préhistoire » en Communications, 54. (p. 198).

13 RICHARD, N. (1992), idem. (p. 203).

14 CARTAILHAC, E. (1902), idem. y CARTAILHAC E. y BREUIL H. (1906), La caverne d'Altamira à Santillana, près Santander (Espagne). Institut de Paléontologie Humaine, Mónaco.

15 LARTET, E. y CHRISTY, H. (1864), idem.

16 CLOTTES, J. (2003b), “De 'art pour l'art' au chamanisme: l'interpretation de l'art préhistorique" en Revue pour l'bistoire du CNRS. Aux Origines de l'Homme. (en línea desde 24 octubre 2006). Consulta 13 de Enero de 2011. (párrafo 21).

17 REINACH, S. (1903) “L'art et la magie á propos des peintures et des gravures de l'age du renne" en L'Anthropologie, 14. (p. 257-266). 
Pero, ¿qué ocurrió con el arte parietal? La academia aceptó la existencia del arte mueble y sus teorías cronológicas e interpretativas, pero no estaba preparada para dar cabida en dicho esquema al arte rupestre. Sólo el descubrimiento de las pinturas de La Mouthe en 1895 creó el campo de posibilidades apropiado para su aceptación y con ello fue inevitable el surgimiento de nuevas interpretaciones. El hallazgo de esta cavidad, por E. Rivière, a través de una entrada obstruida, ponía en entredicho las premisas que anteriormente negaban su existencia, tales como la falta de iluminación ${ }^{18}$. El rechazo de Altamira fue más, por tanto, un choque directo con el discurso científico vigente en el siglo XIX, que un cuestionamiento de las capacidades técnicas/artísticas del hombre paleolítico ${ }^{19}$.

\section{LA UTOPíA Y EL "PARADIGMA DEL PROGRESO"}

Aceptado el arte parietal paleolítico, las publicaciones se multiplican. No tanto los descubrimientos de cuevas decoradas, pues los dispositivos gráficos eran conocidos de antemano ${ }^{20}$, pero no se había creado el contexto académico apropiado para su aceptación y nadie quería revivir el descrédito sufrido por M. S. Sautuola.

A principios del siglo $\mathrm{XX}$, se constituye el paradigma del progreso como interpretación dominante. La revolución industrial (1780-1870) había generado en la sociedad francesa un sentimiento de tranquilidad y superioridad, lo que les permitía demostrar su poder frente al 'primitivo' que habitaba en las zonas colonizadas. Asistimos al gran desarrollo de la antropología y de la sociología, a través de la cual se toma conciencia de una cierta complejidad de las sociedades primitivas vigentes. Los estudios de J. Frazer ${ }^{21}$ y L. Levy-Bruhl ${ }^{22}$ prestarían particular atención a la mentalidad primitiva, a los problemas acerca del origen y el carácter de la magia, y a

18 Aunque ya hemos visto que estas premisas fueron las oficiales, pero no respondían a una contratación científica, sino al estado de la cuestión de la ciencia prehistórica en sus sedes de poder y de conocimiento.

19 MORO ABADÍA, O. y GONZÁLEZ MORALES, M. R. (2004), “1864-1902: El reconocimiento del arte paleolítico" en Zephyrus, 57. (p. 123).

20 En 1895, L. Dumas descubrió una silueta de mamut en la cueva de Chabot. Dos años más tarde, F. Daleau encontró los grabados zoomorfos de Pair-non-pair; el mismo año (que) se produce el hallazgo de Marsoulas, gracias a la labor de F. Regnault y R. Jammes. En septiembre de 1901, L. Capitan, D. Peyrony y H. Breuil descubrieron la caverna de Les Combarelles, y la de Font de Gaume, una semana después.

21 FRAZER, J. G. (1965), La rama dorada. Un estudio sobre Magia y Religión. México. FCE. Madrid.

22 LEVY-BRUHL, L. (1922), La mentalité primitive. Buenos Aires, Lautaro. 
las religiones primitivas ${ }^{23}$, abriendo la puerta a conceptos simbólicos y espiritualistas, y a su aplicación en el arte prehistórico. La existencia de un arte 'primitivo' reciente puso en entredicho la interpretación vigente. El arte paleolítico, por analogía, debía de tener una funcionalidad, un fin. La disposición de las representaciones gráficas en el interior de las cavidades, en lugares de acceso muy restringido, no podían resultar de una actividad inocente y altruista. Como ha afirmado recientemente M. Lorblanchet, «l'extraordinaire effort des Paléolithiques pour une prise de possession totale de la cavité jusque dans ses moindres recoins et jusqu'à la limite de leurs possibilités physiques. Cette volonté de pénétration extrême pour inscrire des marques ou tréfonds de la terre avait certainement une signification symbolique et religieuse $»^{24}$. Este contexto de cambio generó que, en 1924, H. Begouën (discípulo de E. Cartailhac) denunciase la teoría ociosa (el arte por el arte), influido del contexto antropológico. Para él, "l'art pariétal paléolithique doit avoir un but utilitaire, comparable à celui qu'il posséde chez les peuplades primitives actuelles" 25 . La búsqueda de su funcionalidad, llevó a admitir que el hombre paleolítico estaba dotado de sentimientos transcendentes. Sin embargo, en un primer momento, la trascendencia no era reflejo de una religión sino de prácticas mágicas. "La magie est un art qui concerne des actes visant un but practique, alors que la religion est formée d'actes indépendants qui constituent eux-mêmes leur prope fin"26. Así, la magia se unía a la funcionalidad del arte, dando sentido a las grafías de los pueblos cazadores-recolectores; primero, magia de caza para más adelante afirmarse una magia de la fecundación-reproducción. Con el surgimiento de las teorías mágicas, la cavidad paleolítica se transforma en 'santuario', concepto que sigue presente en el vocabulario común de los paleolitistas sin cuestionamiento. "A partir du moment où nous postulons que la grotte ornée est bien un sanctuaire, la problème va être que toute trace laisée par l'Homme préhistorique sera, par cela même, 'sacralisée'. C'est-à-dire, qu'il faudra l'interpreter comme une manifestation symbolique" 27 . En este marco L. Capitan y J. Bouyssonie proponen la teoría de la cueva-catedral, por analogía con la decoración que el mundo occidental cristiano llevaba a cabo en sus santuarios, creando "une atmosphère esthétique et commémorative

23 DURKHEIM, E. (1912) Les formes élémentaires de la vie religieuse (Le Systéme totémique en Australie). Ed. Alcan, Paris.

24 LORBLANCHET, M., (2010), Artpariétal. Grottes ornées du Quercy. Editions du Rouergue. (p. 190).

25 COYE, N. (1997), La prébistoire en parole et en actes, méthodes et enjeux de la pratique archéologique, 1830-1950, Paris, L'Harmattan. (Histoire des Sciences Humaines). (p. 247).

26 LOMBARD, J. (2008), Introduction à l'Ethnologie. COLIN ARMAND. Collection CURSUS. (p. 135).

27 PIGEAUD, E. (2009), « Les rituels des grottes ornées. Rêves de prehistoriens, réalités archéologiques » en halshs-00350622, (version 1-7 Jan 2009). (p. 3). 
pour célébrer ses rites et ses cultes"28.

S. Reinach expuso en 1903 su concepto de 'magia de caza', hallando las bases de su interpretación en las investigaciones de los etnólogos, que promovieron la complejidad de los grupos primitivos, y se mostraron contrarios a la idea del 'salvaje'. Entendió las cuevas como santuarios de invocación, donde tendrían lugar ceremonias y ritos sagrados o propiciatorios, potenciados por el misterio de la oscuridad. Las manifestaciones gráficas representarían la actividad mágica de los pueblos cazadores, tratando de apoderarse o de herir a los animales vivos a través de la ejecución de su imagen. Adquieren, así, estos grafismos, un carácter sacro, místico o religioso; confirmado por la ordenación de las representaciones en la profundidad de las cuevas ${ }^{29}$. El primero de los adeptos a esta interpretación será H. Breuil; el autor que mejor resume el paradigma del progreso vigente en la investigación arqueológica. El estudio in situ de numerosas cavidades franco-cantábricas le llevó a afirmar el carácter sagrado del arte cavernario, aludiendo en su obra La caverne d'Altamira, junto a E. Cartailhac, a numerosos paralelos etnográficos que confirmaban la importancia social y religiosa del dispositivo gráfico estudiado ${ }^{30}$. Para $\mathrm{H}$. Breuil existían una serie de factores que permitían explicar la evolución del arte paleolítico: la calidad artística del dibujo, el dominio de la técnica y la perspectiva (la consecución de la tercera dimensión). Las ideas de H. Breuil condicionaron los trabajos prehistóricos durante la primera mitad del siglo XX, convirtiéndose en el paradigma dominante. La clasificación del arte paleolítico se configuró en torno a dos ciclos de desarrollo gráfico: auriñaco-perigordiense y solutreomagdaleniense, en base a criterios técnicos y estilísticos, que avanzaban desde lo más simple a lo más complejo.

Es el peso de la etnografía y de la antropología lo que dará ímpetu, en la primera mitad del siglo XX, al desarrollo de la disciplina prehistórica en su ámbito cronológico e interpretativo, sin embargo, los resultados no serán siempre sostenidos sobre criterios arqueológicos. Definimos este período como 'utopía interpretativa' pues responde a la aplicación directa de las observaciones etnográficas al campo de la explicación prehistórica; "une vue homogène et utopique des chasseurs-collecteurs du Paléolithique supérieur considérés comme une simple extension du présent ethnographique" ${ }_{31}$. Uno de los ejemplos más destacados es el caso de N. W. G. Macintosh,

28 ANATI, E. (2003), Aux origines de l'art, 50000 ans d'art prébistorique et tribal. Temps Des Sciences. Editions Fayard. (p. 47)

29 RICHARD, N. (1993), « De l'art ludique a l'art magique. Interprétations de l'art parietal su XIX siècle » en Bulletin de la Société Prébistorique Française (BSPF), 90 (1-2). (p. 67).

30 CARTAILHAC E. y BREUIL H. (1906), idídem.

31 LORBLANCHET, M. (1988), "De l'art parietal des chasseurs de rennes à l'arr rupestre des chasseurs de kangourous" en L'Anthropologie, 92 (1). (p. 273). 
arqueólogo y antropólogo australiano ${ }^{32}$. Su estudio demostró (contrario a su deseo) que la interpretación etnográfica nacía con un sesgo cultural, pues los conceptos eran explicados desde el contexto de conocimiento del etnógrafo. Si su aplicación se lleva al ámbito paleolítico, el resultado es, como diría A. Leroi-Gourhan, un doble filtro, "décalage chonologique entre les deux termes de la comparaison" 33 .

Sólo a partir de mediados del siglo XX, las explicaciones basadas en el comparatismo etnográfico pierden fuerza, pues surge la conciencia de que habían aplicado un gran subjetivismo, sin dedicar ningún tiempo a la crítica de los elementos propios de otras sociedades y épocas ${ }^{34}$. La crítica a dicha metodología se vale de tres conceptos fundamentales: descontextualización"les populations paléolithiques étaient engagées dans un processus historique qui s'oppose à l'imbobilisme conservateur des sauvages actuels" 35 presentismo (perspectiva a-histórica) y homogeneización ${ }^{36}$.

\section{LA SOCIEDAD. "LA REVOLUCIÓN SEMÁNTICA" 37 DEL ARTE PALEOLÍTICO}

En el contexto de la Segunda Guerra Mundial, surgen dos tendencias en la Historia de la Ciencia, que van a vehicular el comportamiento y las perspectivas de investigación de una nueva generación de prehistoriadores. El materialismo y el estructuralismo son la clave para comprender el giro de la disciplina ${ }^{38}$, con especial relevancia en los estudios de arte paleolítico.

Tras la revolución de 1917, el materialismo (o marxismo positivista) va a transformar el enfoque del hombre respecto a su historia. Su aplicación busca dar sentido a las relaciones sociales y a las actividades materiales que las

32 MACINTOSH, N. W. G. (1977). "Beswick Greek cave, two decades later: a reappraisal" en UCKO, P. (Ed.), Form in the indigenous art. Caberra. (p.191-197).

33 LEROI-GOURHAN, A. (1960), "Problèmes artistiques de la Préhistoire" en L'information de l'histoire de l'art. Paris. $5^{\circ}$ année, 2. (p. 39-45).

34 BAHN, P. (2001), Journey Through the Ice Age. University of California Press. Berkeley. Los Angeles. (p. 116).

35 GROENEN, M. (1994), Pour une histoire de la Prebistoire. L'Hommes des Origines. Jérôme Millon. (p. 339).

36 CONKEY, M. (1984), "To find ourselves: art and social geography of prehistoric hunter gaterers" en Past and Present in hunter gatherer studies. Academic Press. New York. (p. 253-276).

37 Es una expresión de que emplea D. Vialou para referirse al período a partir de 1960. Citado en VIALOU, D. (2006), La Prébistoire. L’Univers des Formes. Gallimard. Paris. (p. 81).

$38 \mathrm{El}$ materialismo (marxismo positivista) conduce a las excavaciones en extensión que se desarrollan en URSS, mientras que es el estructuralismo el que genera la aplicación de Leroi-Gourhan. Por tanto es cierto, que dos teorías historiográficas convergen en una misma aplicación práctica, la excavación arqueológica en sincronía. 
reflejan; el objeto de estudio es la sociedad y su comportamiento; "la histoire des hommes en liaison avec l'histoire de l'industrie et de l'echange" ${ }^{39}$. Es por ello que se hace necesario analizar la sociedad en términos de sincronía, aplicando una metodología de excavación en extensión, en la que se puedan observar y definir los elementos de la cultura material en su contexto original, estableciendo relaciones entre los artefactos y el espacio en el que se desarrollan. Resulta de ello, la creación del término de cultura material y el surgimiento de estudios en el campo del arte paleolítico que se distancian de las creaciones evolutivas y cronológicas de la diacronía (G. Mortillet, E. Piette o H. Breuil), para centrarse en la sincronía de las manifestaciones gráficas; en un momento concreto de la sociedad paleolítica.

La primera de las aplicaciones fue desarrollada por M. Raphaël ${ }^{40}$, quien afirma la existencia de relaciones espaciales (agrupamientos, aislamientos, figuras yuxtapuestas...) entre las grafías que componen un dispositivo cavernario. Propone una lectura espacial de las obras-que se han dispuesto de manera intencional-, en las que se evidencia, por vez primera, la importancia de los soportes en su desarrollo. Esta línea de investigación tendrá continuidad en la figura de A. Laming-Emperaire, y más tarde en A. Leroi-Gourhan. Este último supone, para muchos, el cambio fundamental de la investigación del arte prehistórico: sus teorías marcaron escuela y aún hoy son base de discusión cronológica para muchos y descrédito para otros. Sea como fuere, el hecho es que su paradigma científico sobrevive en la actualidad y forma, junto a H. Breuil, el eje explicativo (a nivel cronológico e interpretativo) de la disciplina actual.

Avanzado el siglo XX, el debate etnográfico sigue presente. A. Laming-Emperaire articula su discurso en la negación del comparatismo etnográfico, pues 'l'addition d'analogies entre des faits hétérogènes ne constitue pas une preuve" ${ }^{41}$. Sin embargo, dicha radicalidad se evade rápidamente y en pocos años se dedicará al campo de la etnografía, como un "modèle méthodologiquement pertinent et aplicable à la prehistoire" El replanteamiento de la autora se debe a las circunstancias de cambio de

39 MARX, C y ENGELS, F. (1962), L'ideologie allemande. Paris. Editions sociales. (coll. Classiques du marxisme). (p. 27).

$40 \mathrm{Al}$ decir de M. Raphäel “...la búsqueda de la libertad que viven los franceses y españoles en la II Guerra Mundial esté iluminada por el símbolo de las representaciones prehistóricas. Como si las pinturas rupestres fueran el primer acto conocido de la separación real del hombre de la inmediata necesidad y su expresión estética, un ejemplo entre muchos otros que podrá realizar el hombre en su recorrido histórico" RAPHÄEL, M. (1945), Prehistoric cave painting. Bollingen series IV. Nueva York. (traducción de Germán Carvajal, 2009).

41 LAMING-EMPERAIRE, A. (1962), La signification de l'art rupestre paléolithique. Méthode et applications. Université de Paris. Editions. A et J. Picard et Cie. (p. 138).

42 GROENEN, M. (1994), idem. (p. 344). 
la Historia de la Ciencia. El estructuralismo, como metodología de análisis de la realidad, cobra fuerza y con él, autores como C. Levi-Strauss, quien analiza, a través del conocimiento de los pueblos primitivos ${ }^{43}$ las estructuras de parentesco, las estructuras de los mitos y los ritos, el totemismo, el lenguaje... ${ }^{44}$, posibilitando la existencia de un sistema de conceptualización común (estructuras latentes) en el hombre con indiferencia a su cronología. En C. Lévi-Strauss se concentran la influencia de F. Saussure ${ }^{45}$, aplicada al lenguaje humano; de E. Durkheim y sus trabajos sobre la conciencia colectiva y de S. Freud, de quien tomará los presupuestos del subconsciente $\mathrm{y}$ del funcionamiento de la mente humana.

Esta convergencia de teorías en el campo intelectual y su resonancia en el ámbito científico, posibilitará que A. Leroi-Gourhan integre la idea de 'estructura' en la metodología arqueológica, aplicándola tanto en la excavación (en extensión) como en los análisis de arte paleolítico. A. LeroiGourhan comprenderá la excavación como un conjunto de estructuras reflejo de la organización social paleolítica y la cueva decorada como un santuario organizado, en el que las figuras ocupan situaciones que fueron objeto de una elección consciente por sus autores. Negaba la posibilidad de aproximación al conocimiento del arte a través de los utópicos etnógrafos; la interpretación debía basarse en el arte mismo, en el registro arqueológico, mediante el análisis de contenidos (estructuración iconográfica) y del contexto (estructuración espacial). Esta tendencia consideraba el arte como un lenguaje expresivo cuyo significado residía en la sintaxis o situación de los términos, siendo las conexiones la clave para entender el mensaje codificado $^{46}$. Para el prehistoriador, "las distinciones cronológicas no tienen más que una importancia secundaria, porque cabe imaginarse que, generaciones sucesivas de pintores y grabadores han utilizado los mismos emplazamientos tradicionales para figuras de la misma función" ${ }^{\prime 47}$.

43 A partir de 1960 asistimos a la transformación de la idea del 'primitivismo' de la mano de Levi-Strauss de manera que analiza dos tipos de racionalidad humana vinculados a las 'sociedades frías', próximas al punto cero de temperatura histórica y las 'sociedades calientes' para referirse a la sociedad moderna actual.

44 LEVI-STRAUSS, C. (1949), Structures élémentaires de la parenté. Paris; (1955) Tristes tropiques. Paris. Libraire Plon. y (1962), La pensée sawvage. Libraire Plon.

45 Es por ello, que D. Vialou denomina este período (a partir de 1960) como 'revolución semántica’ en VIALOU, D. (2006), La Préhistoire. L'univers des formes. Gallimard. (p. 81).

46 CHAPA BRUNET, T. (2000), "Nuevas tendencias en el estudio del Arte Prehistórico" en Arqueoweb, 2, 3. Departamento de Prehistoria, Universidad Complutense de Madrid. En línea (10-02-2011): http://www.ucm.es/info/arqueoweb/numero2_3/articulo2_3_ CHAPA.htm.

47 LEROI GOURHAN, A. (1984), Arte y grafismo en la Europa Prehistórica. Ediciones Istmo, Madrid. (p. 352-353). 
A pesar de su doxa estructuralista (y por tanto sincrónica), formuló una sucesión evolutiva en cuatro estilos ${ }^{48}$, que si bien pretendía romper con el esquema imperante establecido por H. Breuil, no fue más que puro continuismo de los postulados antiguos, eso sí, avalado por un corpus elaborado y un ejercicio estadístico pormenorizado. Pero, las críticas fueron rápidas ${ }^{49}$. El traslado de los supuestos lingüísticos al análisis social y cultural había hecho alejarse a la antropología (y por extensión, a la prehistoria) del concepto de historia. El sujeto desapareció de la escena; la historia de los hombres fue remplazada por una historia de las estructuras ${ }^{50}$. Tal como postulaba C. Lévi-Strauss, "toute étude situant les phénomènes avec un 'ordre dans le temps': ou bien nos sciences s'attachent à la dimension diachronique des phénomènes, c'est-à-dire, à leur ordre dans le temps, et elles sont incasables d'en faire l'histoire; ou elles essayent de travailler à la manière de l'historien et de la dimension du temps leur échappe"

El estructuralismo se convierte, así, en base de propuestas e hipótesis a mediados del s. XX, que tendrán su seguimiento en los trabajos recientes de G. Sauvet ${ }^{52}$, D. Vialou, F. Criado o A. Hernando ${ }^{53}$. Pero, a partir de 1968 de desarrolla un cambio de perspectiva y surge el post-estructuralismo, como un intento por conciliar el análisis estructural con la historia en diacronía, devolviendo al hombre un papel como individuo en sociedad. La prehistoria se empapa del nuevo contexto ideológico, creado a partir de 1968 y defiende la importancia de "conocer a una sociedad no sólo a través del desarrollo de sus acciones, sino a través de aquello que es obra de un individuo concreto" ${ }^{54}$. Las interpretaciones, sometidas a revisión crítica desde los años

48 LEROI-GOURHAN, A. (1965), Prehistorie de l'Art Occidental. Mazenod. París.

49 LORBLANCHET, M. (1988), ídem. y UCKO, P. y ROSENFELD, A. (1967), Arte Paleolítico. Guadarrama. Madrid.

50 BARROSO, C. (1996), "El paradigma común de los historiadores del siglo XX” en Estudios Sociales. Revista universitara semestral, 10. Santa Fe. Argentina. En línea (10-02-2011): http://www.h-debate.com/cbarros/spanish/paradigma_comun.htm

51 LEVI STRAUSS, C. (1958), Anthropologie structurale. Paris. Libraire Plon. (p, 5).

52 Los trabajos de G. Sauvet son referentes en el estado actual de la investigación del arte paleolítico. Para este autor, el arte puede analizarse como un sistema semiológico en el que cada tema animal se considera como un signo que posee un valor propio, definido por las relaciones que establece con el resto (1979: 349).

53 Alguna de las últimas aportaciones estructuralistas es el trabajo de A. Hernando, quien postula que "existe una relación estructural representación (es una cita textual) a través de metonimias/escaso grado de complejidad socio-económica y a través de metáforas/ elevado grado de complejidad" (HERNANDO, 1997: 247).

54 CHAPA BRUNET, T. (2000), idem. 
setenta, favorecerán nuevos modelos explicativos basados en la semiología ${ }^{55}$ e incluso algunas resucitan la teoría del "arte por el arte" ${ }_{56}$, la funcionalidad mágica ${ }^{57}$ y los criterios de autor ${ }^{58}$. Esta última propuesta, que supone el reconocimiento del autor de la obra gráfica mediante el estudio de su forma, surge de la visión individualista del arte en la sociedad contemporánea, en que se entiende el artista como puro, individual, sin más fines que el arte, independiente a las sanciones del mercado, al reconocimiento social, cerrado en un mundo social particular ${ }^{59}$.

Las nuevas condiciones intelectuales nacidas del post-estructuralismo se fusionan rápidamente con las propuestas de la Nueva Arqueología, surgida a finales de los años 60. El contexto, la sociedad y el paisaje cobran protagonismo en cuanto a explicaciones del fenómeno gráfico. Serán los autores anglosajones-M. W. Conkey, C. Gamble, P. Ucko o L. G. Straus ${ }^{60}$ los nuevos 'hombres fuertes' de la Prehistoria europea. En cuanto al arte paleolítico, destacarán su papel como transmisor de información y elemento activo de interacción social entre los grupos humanos. Como otra actividad

55 SAUVET, G. y WLODARCZYK, A. (1977), "Essai de sémiologie préhistorique (Pour une théorie des primers signes graphiques de l'homme" en Bulletin de la Société Préhistorique Française (BSPF), 74. (p. 545-558) y SAUVET, G. (1988), « La communication graphique paléolitique. De l'analyse quantitative d'un corpus de donées à son interprétation sémiologique » en L'Anthropologie, 92. (p. 3-16).

56 HALVERSON, J. (1987), «Art for Art's Sake in the Paleolithic,» en Current Anthropology, 28. (p. 63-89) y LORBLANCHET, M. (1995), Les grottes ornées de la Préhistoire, nouveaux regards. Ed. Errance.

57 CLOTTES, J. y LEWIS WILLIAM, D. (1996), Los chamanes de la prehistoria, tránsito y magia en las cuevas decoradas. Ariel, Barcelona.

58 APELLÁNIZ, J. M., (1987). "La Aplicación de técnicas estadísticas al análisis iconográfico y al método de determinación de autor”. Munibe 39-40: 39-59; APELLÁNIZ, J. M. y CALVO GÓMEZ, F. (1999), La forma del arte paleolítico y la estadística. Análisis de la forma del arte figurativo y su tratamiento estadístico. Universidad de Deusto. Bilbao.; RUIZ IDARRAGA, R. (2003a), Metodología del análisis del arte prehistórico. El estilo del autor y el estilo del grupo. Kobie, Anejo 5. Bilbao; y RUIZ IDARRGA, R. y APELLÁNIZ, J. M. (1998/1999), "Análisis de la forma y de la ejecución de las figuras grabadas de la cueva de Venta Laperra (Carranza, Bizkaia)" en Kobie, 25. (p. 94-140).

59 BOURDIEU, P. (1994), Razones prácticas sobre la teoría de la acción. Barcelona, Anagrama. (p. 183).

60 CONKEY, M. W. (1997) "Beyond Art and between the caves: thinking about context in the interpretive process" en CONKEY, M. W. (Ed.), Beyond Art. Pleistocene Image and Symbol. San Francisco, California. (p. 343-367). GAMBLE, C. (2001), Las sociedades paleoliticas de Europa. Ariel, Barcelona; UCKO, P. y ROSENFELD, A. (1967), idem. y STRAUS, L. G. (1983a), El Solutrense vasco-cantábrico. Una nueva perspectiva. Centro de Investigación y Museo de Altamira. Monografías, 10. Ministerio de Cultura. Madrid. 
social más, el fenómeno gráfico será vinculado a otras dinámicas como la exogamia (medida de regulación biológica de los grupos), la iniciación de los adolescentes en la caza, la transmisión de conocimientos (tecnología y modos de trabajo) y la adquisición de materias primas. Es, desde este prisma, desde el que es lícito analizar el arte paleolítico como elemento transmisor y canalizador de las actividades de la sociedad del pasado, una idea sobre la que volveremos posteriormente.

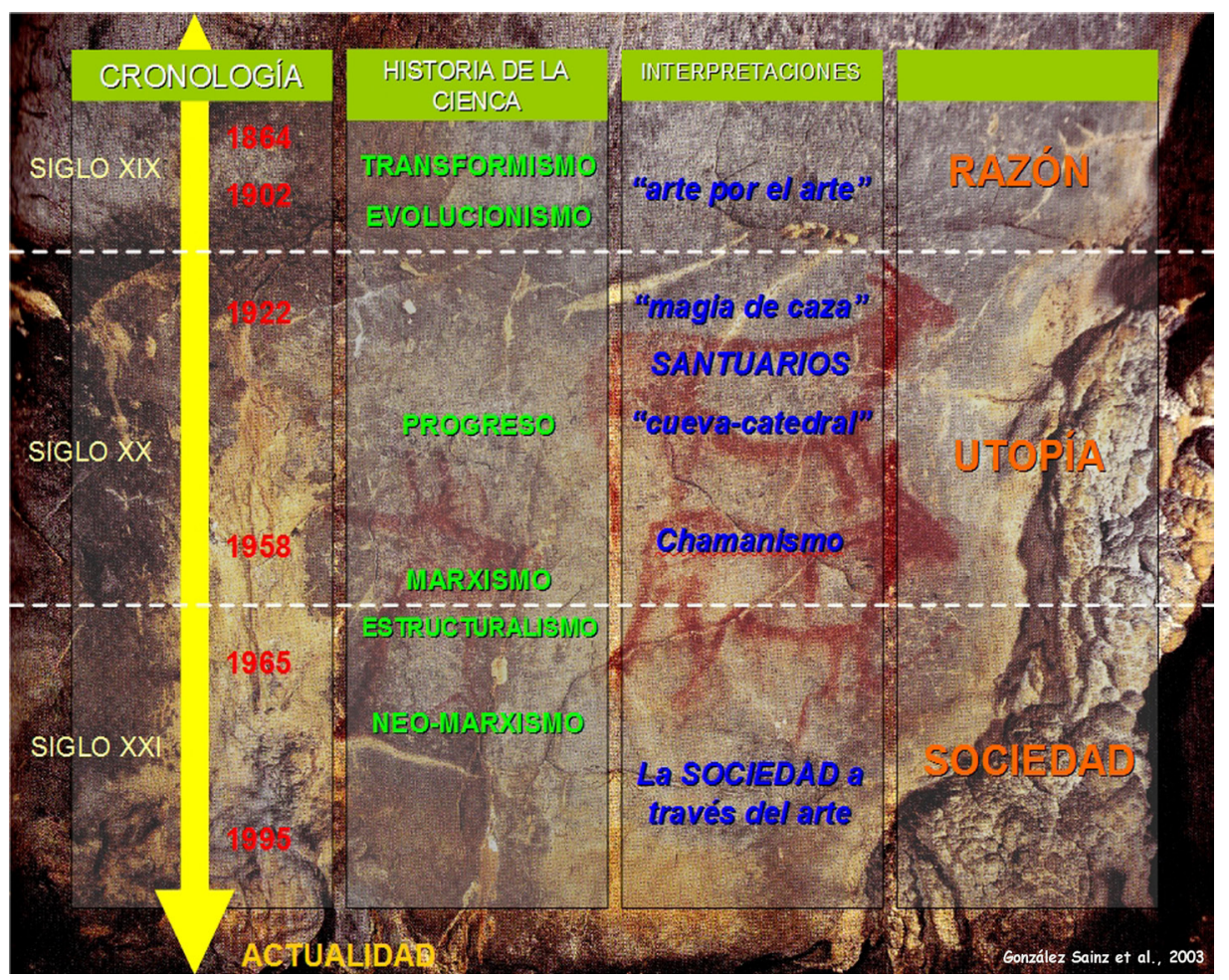

Fig.1. Cuadro sintético de las diferentes corrientes de pensamiento que tienen su correspondencia en las teorías interpretativas del arte paleolítico.

5. LA ACTUALIDAD. C14 y EL NACIMIENTO DEL 'PESIMisMO' EN EL ARTE PALEOLÍTICO

La segunda mitad el siglo XX creó las bases de la disciplina oficial, esa que se imparte en las universidades, casi por unanimidad, desde el paradigma positivista e histórico-cultural, que ordena el arte paleolítico a través de la deducción y posterior clasificación de A. Leroi-Gourhan. Por otro lado, los estudios e interpretaciones sobre el arte paleolítico dejaron de ser monopolio de la Academia occidental. A. Marschack analizó el arte europeo y asiático como resultado de una cuantificación temporal 
o calendario ${ }^{61}$ y otra americana, M. Gimbutas desarrolló una teoría de exaltación de la feminidad a través de las grafías, posibilitando el culto a una diosa madre ${ }^{62}$. El año anterior, 1988, con motivo del Congrès Internacional de Darwin, O. Odak reprochó, de forma contundente, la utilización del término 'arte' para los conjuntos de grafismos paleolíticos, aludiendo a su anacronismo conceptual. M. Conkey se había posicionado ya, al respecto, afirmando el carácter estético del término ${ }^{63}$. Esta agitación, en las filas académicas, supone, en opinión de M. Lorblanchet, una gran exageración, del mismo calibre que la creada por la interpretación del 'arte por el arte'. Ésta, porque suponía una teoría ociosa radical y la más reciente, por anular la capacidad de creación estética del hombre, a la sombra de sus necesidades funcionales ${ }^{64}$. Un nuevo intento, por descargar el concepto estético del término arte, es protagonizado por M. Chollot-Varagnac, alumna de A. Leroi-Gourhan y defensora de la relación de las grafías con una escritura primitiva. Para esta prehistoriadora, la labor del investigador no consiste en encontrar satisfacción artística sino en descifrar la vida social de los orígenes de la humanidad ${ }^{65}$.

Desde principios de la década de los 90, una serie de prehistoriadores (M. Lorblanchet, P. Bahn y J. Clottes, a la cabeza ${ }^{66}$ ) reaccionan contra la cronología estilística de A. Leroi-Gourhan, demostrando la larga frecuentación de las cavidades decoradas y la construcción progresiva de los dispositivos gráficos, en contra de la visión sincrónica que había establecido la escuela estructuralista. Esta reacción radical supone una negación de los estilos como elementos de comparación, introduciendo, para algunos, un enorme relativismo en los estudios de arte paleolítico. La continua búsqueda de datos y esta 'era post-estilística' llevada a su extremo han supuesto el

61 MARSHACK, A. (1970), "Le bâton de commandement de Montgaudier (Charente). Réexamen au microscope et interprétation nouvelle » en L'Anthropologie, 74. (p. 321-352).

62 GIMBUTAS, M. (1989), The language of the Goddess. Harper San Francisco.

63 CONKEY, M. (1987), "New approaches in search for meaning? A review or research in Paleolithic Art" en Journal of Field Archaeology, 14. (p. 413).

64 LORBLANCHET. M. (1992), "Le triomphe du naturalisme dans l'art paleolithique" en SHAY, T. y CLOTTES, J. (1992), The limitations of Archaeological Knowledge. Etudes et Recherches Archéologiques de l'Université de Liège, 49. (p. 115).

65 CHOLLOT-VARAGNAC, M. (1980), Les Origines du Graphisme symbolique. París. (p. 18).

66 CLOTTES, J. (1995), "Les peintures de la Grotte Chauvet Pont d'Arc, á Vallon Pont d'Arc (Ardèche, France): datations directes et indirectes par la methode du radiocarbone" en Comptes-Rendus de la Académie des Sciences de Paris, 320, serie IIa, Paris. (p. 11131140) ; LORBLANCHET, M. (1995), Les Grottes ornées de la Prehistoire ; noveaux regards. Ed. Errance, Paris ; LORBLANCHET, M. (1999), La naissance de l'art. Genèse de l'art préhistorique. Ed. Errance, Paris. CLOTTES, J. y BAHN, P. (2003), Chawvet Cave. The art of earliest times. University of Utah Press. 
nacimiento de lo que T. Dowson denomina 'cronocentrismo'67. "Muchos autores objetivistas/positivistas, de hecho, han demostrado una auténtica obsesión por la escala temporal, dedicándole muchas páginas a las dataciones absolutas, e, incluso, pareciendo que datar es la finalidad de la práctica

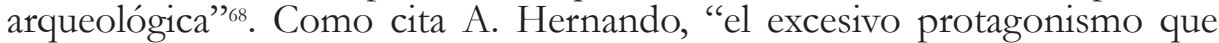
los arqueólogos concedemos, en ocasiones, a la cultura material no es sólo resultado de una carencia empírica de otras informaciones sobre el pasado, sino esencialmente, de una carencia conceptual en la que los propios arqueólogos elegimos situarnos. Porque, en lugar de mantener presente que la cultura material es una perspectiva desde la que analizar el pasado, lo que caracteriza a la Arqueología, siendo el pasado en sí, sus sociedades y sus gentes el objetivo de la investigación, convertimos aquella en el objeto final, en la meta improrrogable de la reflexión" ". Es por ello que un número creciente de especialistas han abandonado la búsqueda de interpretaciones, prefiriendo dedicar su tiempo a elementos tangibles ${ }^{70}$. El tiempo y la cronología han ensombrecido el desarrollo de interpretaciones, de lecturas sociales. J. Clottes afirma que estamos en un momento de pesimismo en cuanto a las interpretaciones; de vuelta al positivismo ${ }^{71}$, pues "como ya decía Pascal (...) la idea o el ideal dogmático de un conocimiento absoluto es lo que conduce al escepticismo" 72 .

La clave para comprender esta involución_pues supone una vuelta la rigidez científica de finales del XIX — reside en el descubrimiento de la cueva de Chauvet $^{73}$, poniendo fin a la idea de progreso que había sostenido las interpretaciones respecto del arte paleolítico hasta el momento ${ }^{74}$. El

67 DOWSON, T. A. (1998), « Homosexualitat, teoria queer i arqueología” en Cota Zero, 14. (p. 85).

68 FALQUINA, A.; MARÍN SUÁREZ, C. y ROLLAND, J. (2006), “Arqueología y práctica política. Reflexión y acción en un mundo cambiante” en Arqueoweb, 8. (1). En línea (10-022011): http://www.ucm.es/info/arqueoweb/numero8_1/conjunto8_1.htm.

69 HERNANDO, A. (1997), "Sobre la Prehistoria y sus habitantes: mitos, metáforas y miedos" en Complutum, 8. (p. 251).

70 BAHN, P. (2001) “Comment regarder l'art pariétal préhistorique?” en Diogène, 1 (193). (p. 114-121).

71 CLOTTES, J. (2003), "De 'l'art pour l'art' au chamanisme: l'interpretation de l'art préhistorique" en Revue pour l'bistoire du CNRS. Aux origines de l'homme. En línea (13/01/2011): http://histoire-cnrs.revues.org/553.

72 BOURDIEU, P. (2000-01), ídem. (p. 14).

73 Y junto a ella, el hallazgo de los dispositivos de Cosquer, Cussac y el arte al aire libre del Valle del Côa.

74 MORO ABADÍA, O. y GONZÁLEZ MORALES, M. R. (2006), "La idea de progreso en el estudio del arte parietal paleolítico: pasado, presente y ...futuro?" en Zephyrus, 59. (p. 160). 
dispositivo gráfico de la cavidad y su antigüedad contradicen una evolución paulatina del dominio gráfico por parte del hombre paleolítico. El duro golpe que reciben los paradigmas explicativos sobre los que se había apoyado, hasta hace apenas un par de décadas, la disciplina arqueológica, obliga a dar marcha atrás. Sin embargo, es bien sabido que sólo es lícito dar marcha atrás para coger impulso. El vuelco repentino ha generado lo que M. Díez-Andreu denomina "el despertar historiográfico" 75 . Numerosos son los autores que han focalizado su investigación en conocer la genealogía de su ciencia, la génesis de sus conceptos y el contexto histórico-social en el que han surgido los paradigmas e interpretaciones. Nuestra aportación es sólo un eslabón más de la cadena que han iniciado otros ${ }^{76}$. Si las nuevas aportaciones provenientes de las llamadas 'ciencias puras' (análisis químicos, geomorfológicos, o palinológicos) tambalean el edificio, es imprescindible volver a cimentar. Y para ello, algo es primordial, plantear cuál es el fundamento de nuestra ciencia, cuál su objeto y fin, ya que por definición es ciencia social.

\subsection{La sociedad detrás del arte: simbolo y lenguaje en el arte paleolitico}

$\mathrm{El}$ avance vertiginoso de la disciplina (con un crecimiento exponencial de los descubrimientos y de los equipos de investigación) nos invita a coger aire. El planteamiento expuesto nos obliga a tomar partido en la concepción teórica de la investigación actual, postulando que el fin del estudio del arte paleolítico no debe ya responder a una ordenación de fases gráficas a partir de una lectura estilística y estética de las representaciones, sino que debe guiarse por los fundamentos de la Sociología del arte ${ }^{77}$, pues nuestro sujeto (por tanto, sujeto histórico) es la sociedad paleolítica; el grupo humano gestor y autor del arte que analizamos como un elemento más de la cultura material fosilizada en su contexto primario. Nuestro objeto de investigación son las sociedades concretas, como totalidades históricas ${ }^{78}$. "L'art n'est pas le reflet statique et figé d'une culture, mais une matière dynamique dont se sert l'artiste pour

75 DÍEZ-ANDREU, M. (2002). Historia de la Arqueología. Madrid: Ediciones Clásicas. Estudios. (p. 36).

76 RICHARD, N. (1993), ídem.; MORO ABADÍA, O. (2005), "Pour une nouvelle histoire des sciences humaines: Lartet, Mortillet, Piette et les temps de la Préhistoire" en Bulletin de la Société Prébistorique Française, 102(4). (p. 715-720); MORO ABADÍA, O. y GONZÁLEZ MORALES, M. R. (2005), "Presente-pasado. Definición y usos de una categoría historiográfica en la historia de la ciencia: El arte prehistórico como paradigma" en Complutum, 16. (p. 59-72); y GROENEN, M. (1994), Pour une histoire de la Prehistoire. L'Hommes des Origines. Jérôme Millon.

77 BOURDIEU, P. (1968), Sociología del arte. Ediciones Nueva Visión. Colección Teoría e investigación en ciencias: sociales dirigida por José Sazbón. Buenos Aires.

78 BATE, L. F. (1989), “Notas sobre el materialismo histórico en el proceso de investigación arqueológica" en Boletín de Antropología Americana, 18. (p. 19). 
exprimer révéler et modeler l'identité culturelle de sa communauté, en même temps que sa prope identité" 79 . El arte es un vehículo de aproximación a la sociedad paleolítica en cuanto que transmite información, convirtiéndose en una escritura que nos proporciona datos respecto a la situación de los grupos humanos en el territorio, de su actividad, intereses económicos y elementos ideológicos. "Las representaciones prehistóricas componen un lenguaje que nos habla acerca de las formas de vida y organización social de los grupos paleolíticos. Un lenguaje, eso sí, codificado, pero que transmitiría mensajes reconocibles e interpretables para aquellos que los practicaban y conocían por formar parte de un grupo" ".0. La información, que aparece codificada, se estructura en función de los marcos teóricos de la sociedad que la creó, por lo que no podemos traducirla y obtener de ello una interpretación unívoca. Sin embargo, sí podemos evaluar los elementos recurrentes presentes en diversos yacimientos, algunos localizados a cientos de kilómetros de distancia. Dicha constatación se ha analizado a través de la formulación de 'territorios

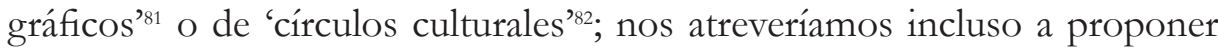
'circuitos culturales' ya que responden al contacto entre grupos humanos que interactúan en constante movimiento. Así, encontramos actualmente propuestas que identifican el grafismo paleolítico como un medio de expresión o hecho comunicativo, que incardina el hombre del pasado con el espacio dentro del que se mueve y actúa. Para ello es esencial comprender el contexto de acción y el marco arqueológico de las representaciones ${ }^{83}$. En las últimas décadas, no son pocos los investigadores que han rectificado el

79 SAUVET, G. (1994), "Rhétorique de l'image préhistorique" en Psychanalyse et Prébistoire. Monographies de la revue française de psychanalyse. (p. 115).

80 PASCUA, F. (2005), "El arte paleolítico: Historia de la investigación, escuelas interpretativas y problemática de su significado" (en línea) en Arqueoweb, 7 (2). Septiembre/ diciembre 2005. En línea (10-02-2011): http://rupestreweb2.tripod.com/artepaleolitico. html.

81 GARCÍA DÍEZ, M. y EGUIZÁBAL TORRE, J. (2003), La cueva de Covalanas. El grafismo rupestre y la definición de territorios gráficos en el Paleolitico cantábrico. Consejería de Cultura, Turismo y Deporte del Gobierno de Cantabria. Santander; y GARCÍA DÍEZ, M. (2001), Comportamiento gráfico durante el Paleolítico Superior en el Alto Asón: análisis de los dispositivos iconográficos rupestres. Tesis Doctoral inédita. Universidad del País Vasco.

82 En terminología de GRAEBUER a partir de FRITZ, C.; TOSELLO, G. y SAUVET, G. (2007), "Groupes ethniques, territoires, echanges: la 'notion de frontière' dans l'art magdalénien" en CAZALS, N.; GONZÁLEZ URQUIJO, J. y TERRADAS, X. (Eds.), Frontières naturelles et frontières culturelles dans les Pirénées prébistoriques. Actes Table Ronde. Tarascone sur Ariège. Publicaciones Universidad de Cantabria. Santander. (p.166).

83 BALBÍN, R. y ALCOLEA, J. J. (1999), «Vie quotidienne et vie religieuse. Les sanctuaires dans l'Art Palélithique » en L'Anthropologie, 103. (p. 23-49) ; y BALBÍN, R. y BUENO, P. (2000), "El análisis del contexto en el arte prehistórico de la Península Ibérica. La diversidad de asociaciones" en Arkeos, 10. (p. 91-127). 
rumbo adoptando esta nueva perspectiva. En el ámbito peninsular, se han desarrollado trabajos orientados al estudio y a la integración del fenómeno gráfico dentro de la reconstrucción histórica de los grupos humanos del pasado $^{84}$, afirmando la existencia de modos regionales de representación como respuesta a una 'cultura oral inter-territorial's5. La explicación es simple: un determinado grupo paleolítico, cazador-recolector y con un desarrollo nómada, se movería en un territorio determinado en el que actúa, transformando la naturaleza y creando una serie de artefactos y elementos simbólicos que componen su cultura. En su actividad cotidiana entrará en contacto con otros grupos vecinos estableciendo relaciones a corta, media o larga distancia; lo que supone un proceso de aculturación, transmisión y aprendizaje entre sus miembros ${ }^{86}$. El estado actual de nuestros conocimientos no nos permite argumentar el carácter de los contactos, la cotidianeidad de los mismos o su fin, pero sí su existencia, creando un mapa de poblamiento, actuación e interacción - con el medio y con otros grupos humanos-de la sociedad paleolítica que incluye los yacimientos arqueológicos, lugares de hábitat, cazaderos, cavidades decoradas y un rico arte al aire libre.

\section{Conclusiones}

A través del presente artículo hemos pretendido ofrecer una visión de la influencia de las ideas y de los contextos sociales en el desarrollo de la disciplina prehistórica, y más concretamente en los estudios de arte paleolítico. 'L'étude de l'art préhistorique n'est pas un domaine secret, hors du temps; comme toute science, elle participe, consciemment ou non, au movement du savoir dont elle bénéficie et qu'elle alimente tout à la fois" ${ }^{87}$. Hemos recorrido los diversos paradigmas de pensamiento, propios y ajenos a la Prehistoria, los dogmas impuestos y las perspectivas más recientes. Ahora, todo

84 MOURE, J. A. (1999a) Arqueología del Arte prehistórico en la Península Ibérica. Ed. Síntesis. Madrid; MOURE, J. A. (1999b), "Arte rupestre y cambio cultural en el final del Paleolítico en Cantabria" en I Encuentro de Historia de Cantabria, I. Santander. (p. 167-190); GONZÁLEZ SAINZ, C. y GONZÁLEZ MORALES, M. (1986). La prehistoria en Cantabria. Ediciones Tantin. Santander; MOURE A. y GONZÁLEZ MORALES A. (1992), La expansión de los cazadores. Paleolítico Superiory Mesolítico en el Viejo Mundo. Ed. Síntesis, Madrid.

85 CANTAlejO, P.; MAURA, R.; ESPEjO, M. M.; RAMOS, J.; MEDIANERO, J.; ARANDA, A.; CASTAÑEDA, V. y CÁCERES, I. (2004), “Cueva de Ardales (Málaga): Testimonios gráficos de la frecuentación por formaciones sociales de cazadores recolectores durante el Pleistoceno Superior" en Sociedades recolectoras y primeros productores. Actas de las Jornadas Temáticas Andaluzas de Arqueología. Ronda. (p. 123 -138).

86 LAYTON, R. (2000), "Shamanism, Totemism and Rock Art. Les Chamanes de la Préhistoire, en the Context of Rock Art Research en Cambridge Archaeological Journal, 10. (p. 169-186) y MITHEN, S. (1991), "El arte de los Cazadores Paleolíticos" en Mundo Científico 117-11. Madrid. (p. 972-979).

87 LORBLANCHET, M. (1992), ídem. (p. 130). 
cobra sentido, conociendo el porqué de la ciencia prehistórica actual. Pero no debería quedar en un análisis crítico sino desarrollar en el investigador un nuevo punto de partida (político y activo). Como ciencia social, la Prehistoria, y como objeto de estudio, el arte paleolítico, deben ser reflexionados en su cotidianeidad práctica y en el fin de la profesión investigadora. Anclar sólidamente las bases teóricas, generará nuevas percepciones de la realidad, propuestas e interpretaciones. Desde este ‘despertar histórico' deberíamos conducirnos hacia el 'optimismo' basado en la rigurosidad del trabajo y la reflexión continua sobre las interpretaciones, "pues sólo de ella(s) puede alimentarse la crítica que permite corregir caminos errados y estimula la creatividad en la investigación" $" 88$. En segundo lugar, es necesario levantar la vista del ordenador - y la autora también debe aplicarse a ello_-y advertir el fin social de nuestra profesión. Nuestro objeto de trabajo es Patrimonio universal, legado por las sociedades pasadas, lo que implica su conocimiento por parte de la sociedad actual y nuestro papel como transmisores de dicha información. El esfuerzo de divulgar las investigaciones no debe ser tanto una obligación curricular, como una postura ética respecto a la sociedad en que vivimos. "La maravillosa lección de una humanidad primitiva a la que se consideraba como apenas salida de la tiranía de los instintos (...) no debe ser olvidada y hemos de hacernos dignos del privilegio de ser depositarios de este excepcional tesoro conociéndolo, estudiándolo, conservándolo y entregándolo a las futuras generaciones después que haya servido para hacer mejor a nuestra sociedad"89.

88 BATE, L. F. (2000), “Teorías y Métodos en Arqueología. ¿Criticar o proponer?” en XIII Congreso Nacional de Arqueología Argentina. Córdoba. (p. 7).

89 GONZÁLEZ SAINZ, C. y GONZÁLEZ MORALES, M. (1986), La Prehistoria en Cantabria. Ediciones Tatín. Santander. (p. 156). 
